$0032-0633(94) 00223-1$

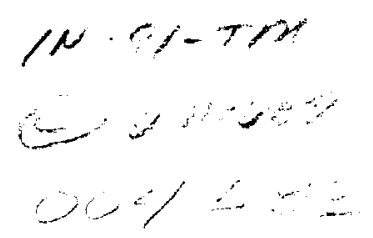

\title{
Oxygenic photosynthesis and the oxidation state of Mars
}

\author{
Hyman Hartman and Christopher P. McKay \\ NASA Ames Research Center, Moffett Field, CA 94035. U.S.A. \\ Received 18 March 1994 ; revised 2 November 1994; accepted 28 November 1994
}

\begin{abstract}
The oxidation state of the Earth's surface is one of the most obvious indications of the effect of life on this planet. The surface of Mars is highly oxidized, as evidenced by its red color, but the connection to life is less apparent. Two possibilities can be considered. First, the oxidant may be photochemically produced in the atmosphere. In this case the fundamental source of $\mathrm{O}_{2}$ is the loss of $\mathrm{H}_{2}$ to space and the oxidant produced is $\mathrm{H}_{2} \mathrm{O}_{2}$. This oxidant would accumulate on the surface and thereby destroy any organic material and other reductants to some depth. Recent models suggest that diffusion limits this depth to a few meters. An alternative source of oxygen is biological oxygen production followed by sequestration of organic material in sediments - as on the Earth. In this case, the net oxidation of the surface was determined billions of years ago when Mars was a more habitable planet and oxidative conditions could persist to great depths, over $100 \mathrm{~m}$. Below this must be a compensating layer of biogenic organic material. Insight into the nature of past sources of oxidation on Mars will require searching for organics in the Martian subsurface and sediments.
\end{abstract}

\section{Introduction}

The Biology Experiments on the Viking missions to Mars detected an unexpected reactivity in the Martian soil. This reactivity manifested itself in the release of $\mathrm{O}_{2}$ from the soil upon humidification (Oyama and Berdahl, 1977). The release was at levels of $70-770 \mathrm{nmol} \mathrm{cm} \mathrm{cm}^{-3}$, much larger than expected from adsorption theory (Ballou et al., 1978). In addition, when a radiocarbon labeled nutrient solution was added to the Martian soil radioactive $\mathrm{CO}_{2}$ was released (Levin and Straat. 1977). These reactions are thought to arise from distinct mechanisms since the $\mathrm{O}_{2}$ release was not altered by heating while the $\mathrm{CO}_{2}$ release was destroyed by prolonged exposure to temperatures

Correspondence to: C. P. McKay near $100 \mathrm{C}$. Further indication of the reactive nature of the Martian soil is the absence of organic materials at the ppb level (Biemann et al., 1977). Unfortunately, the Viking landers could not sample soils below about 10 $\mathrm{cm}$ and so the depth of these organic-free, apparently oxidizing, soils is unknown. Gooding (1992) has pointed out that the class of meteorites known as the SNCof putative Martian origin -are also oxidizing with the dominant forms of $\mathrm{C}$ and $\mathrm{S}$ being carbonate and sulfate and iron being ferric. These meteorites date back from 200 to 1300 million years suggesting oxidizing conditions on the near surface of Mars at least that long ago (Gooding, 1992).

Mars should not be red, it should be grey. The infall of meteoritic material should be a net source of organics at the present time and throughout Martian history (Biemann et al., 1977). In fact, models for the late accretion of volatiles and organics to the Earth and Mars suggest that the surface of Mars should have been rich in organic material due to infalling comets (Chyba et al., 1994). Organic material destroyed by the shock of entry would produce a gas of reducing nature because the $\left(\mathrm{H}_{2}+\mathrm{C}\right) \mathrm{O}$ ratio is greater than unity.

In this paper we consider two possible sources of oxidation on Mars: photochemical and biological. Photochemical production of oxidants occurs due to the photolysis of $\mathrm{H}_{2} \mathrm{O}$ and the loss of $\mathrm{H}_{2}$ to space. This process is known to be occurring in the present atmospheres of Mars and Earth. Biological production of oxidants results when photosynthesis utilizes $\mathrm{H}_{2} \mathrm{O}$ as the terminal electron donor in the production of organic material from $\mathrm{CO}_{2}$. Net accumulation of $\mathrm{O}_{2}$ results if this organic material is buried in sediments. Clearly photochemical oxidant production is occurring on Mars, the question of interest here is whether oxygenic photosynthesis ever occurred there, and the record, if any, it has left in the sediments.

\section{Photochemical oxidant production}

It has been suggested that atmospheric photochemistry is producing $\mathrm{H}_{2} \mathrm{O}_{2}$ in the Martian atmosphere and that the 
deposition of these molecules onto the soil is a source of oxidizing power (Hunten, 1979; Bullock et al., 1994). The standard model used to explain the liking Biology Experiment results invokes the existence of at least two oxidants in the Martian soil, a thermally stable oxidant such as $\mathrm{KO}_{2}$ or $\mathrm{CaO}_{2}$ as well as a thermally labile oxidant such as $\mathrm{H}_{2} \mathrm{O}_{2}$ (Klein, 1978; Zent and McKay, 1994), presumably both are derived from atmospheric $\mathrm{H}_{2} \mathrm{O}_{2}$.

It is important to note here that the production of net oxidation on Mars at the present time is zero because for every $\mathrm{H}_{2}$ molecule that escapes one $\mathrm{O}$ atom escapes as well (McElroy et al., 1977; Liu and Donahue. 1976) thus effectively resulting in the escape of $\mathrm{H}_{2} \mathrm{O}$. Only if the $\mathrm{H}_{2}$ escapes and the $O$ is left behind is there a net source of oxidant. Presumably if there were a sink for $O$ on the surface--as would have occurred early in Martian history - there would be a net production of oxidant. In a recent theoretical paper Fox (1993) has suggested that the escape flux of $\mathrm{O}$ may not balance the $\mathrm{H}_{2}$ loss. If these calculations are correct, this could imply that there remains a surface sink of $O$ or, alternatively that the present atmosphere is not in steady state.

Despite uncertainties in our understanding of the redox balance of the present Mars atmosphere the photodissociation rate of $\mathrm{H}_{2} \mathrm{O}$ is an upper limit to the photochemical production of oxidant on Mars. The present rate of oxidant production due to photolysis of water, about $6 \times 10^{7} \mathrm{~cm}^{-2} \mathrm{~s}^{-1}$ (Liu and Donahue, 1976; McElroy et al., 1977), would produce a layer of iron oxide about $10 \mathrm{~m}$ thick over 3 billion years if there were no escape of $\mathrm{O}_{2}$.

Recent modeling studies suggest that the depth of the penetration of $\mathrm{H}_{2} \mathrm{O}_{2}$ the likely photochemical oxidant and at least the most mobile - is small. Bullock et al. (1994) developed a coupled soil/atmosphere transport model for $\mathrm{H}_{2} \mathrm{O}_{2}$ on Mars. Their results suggest that the concentration of $\mathrm{H}_{2} \mathrm{O}_{2}$ in the soil goes 10 zero at a finite depth, a consequence of nonlinear diffusion in the soil. A significant result of their model is that for a wide range of $\mathrm{H}_{2} \mathrm{O}_{2}$ lifetimes (up to $10^{5}$ years), the extinction depth was found to be less than $3 \mathrm{~m}$. Thus only a fraction of the potential total photochemical oxidation is realized with the rest escaping to space as $\mathrm{O}_{2}$. The depth of the oxidizing layer in this case $(10 \mathrm{~m})$ is shown in Fig. 1 .

It is possible that the escape rate was much higher in the past. The $\mathrm{D} / \mathrm{H}$ ratio on Mars is six times the terrestrial value (Owen et al., 1988) which may support this suggestion. Alternatively, the $\mathrm{D} / \mathrm{H}$ value may simply reflect equilibration over geologically recent times of only that water in the exchangeable atmosphere surface reservoirs (Carr, 1990). However, the depth of oxidation is fundamentally limited by the ability of oxidants to diffuse into the soil. This may be enhanced due to gardening of the soil layers by meteors and wind action but these effects have only mixed the top few meters of the Martian surface in the last few billion years (Flynn and McKaly, 1990: Arvidson, 1986).

On a warm early Mars, in the presence of liquid water, transport of oxidants to depths may not have been limited by diffusion. However, it is unknown if in a thicker, warmer, atmosphere photochemistry would be still able to produce oxidants and at what level. Nonetheless, while

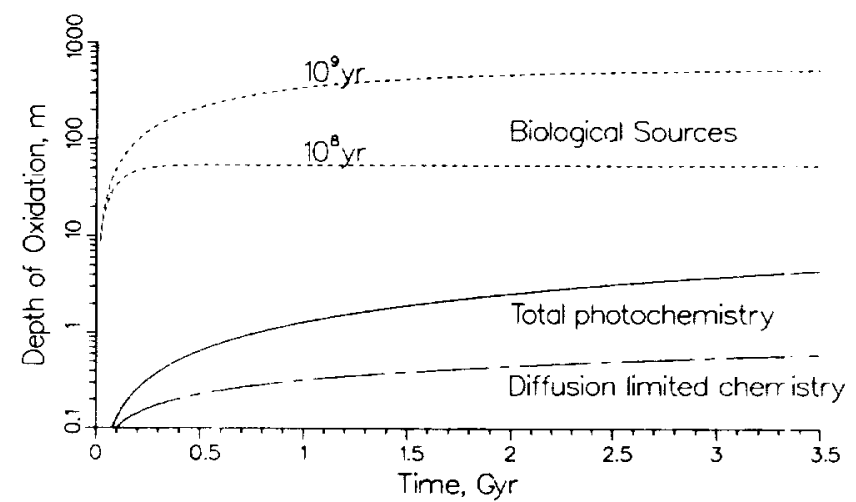

Fig. 1. Depth of oxidation over time for several cases. The iolid line refers to the present photochemical production of oxidant assuming an initial reducing state of the Martian surface and ignoring diffusion limitations. The long-dash line refines this model by using the diffusion model of Bullock et al. (1994). The upper dashed lines show the results for a presumed biological source of $\mathrm{O}_{2}$. Here the net accumulation of oxygen is detern ined by the rate of sediment burial for the early Earth (DesMarais 't al. 1992). The two cases correspond to exponential decline ifter $3.8 \mathrm{Gyr}$ ago with timescales of $10^{8}$ and $10^{4}$ years

oxidation to depths greater than tens of meters might indicate that there was an alternative source of oxidant on Mars it might also be explained by invoking alternc tive abiotic processes.

\section{Biological source}

Life is a plausible source because there is consider able evidence that the early environment on Mars, 3.5 Gyr ago, was characterized by liquid water on the surface and possibly a dense atmosphere of $\mathrm{CO}_{2}$ and $\mathrm{N}_{2}$ (Pollack et al., 1987: Kasting, 1991). From studies of the Eath's earliest biosphere we know that by this time life had ( riginated on the Earth (Awramik et al., 1983; Schopf, 1983). The types of cells detected suggest the presence of cy: nobacteria, and therefore $\mathrm{O}_{2}$ producing photosynthesis, at that time (Schopf and Packer, 1987; Schopf, 1993; Awramik, 1992).

The development of oxygenic photosynthesis is problematical in that it appears to require prior aerobic conditions to promote tolerance of oxidative products and dependence on the more energetically costly mode of splitting water in photosynthesis (Towe, 1978; Fridovich, 1978). Atmospheric models of the early Earth show hat photolysis of water is simply not able to alter the redox balance of the global environment (Kasting and Walker, 1981; Levine et al., 1982). To resolve this paradox we have proposed a scenario involving the photochemical production of $\mathrm{H}_{2} \mathrm{O}_{2}$ in the atmosphere acting to remove the reductants from local lakes or basins (McKay and Hartman. 1991). Without reductants photosynthetic organisms would have had no choice but to use water as the terminal electron donor. In addition, the presenci: of $\mathrm{H}_{2} \mathrm{O}_{2}$ would have promoted the development of enzy nes such as catalase that protect against reactive oxidants. With no reductants available and with the biochemical machinery necessary to protect against oxic byprodicts 


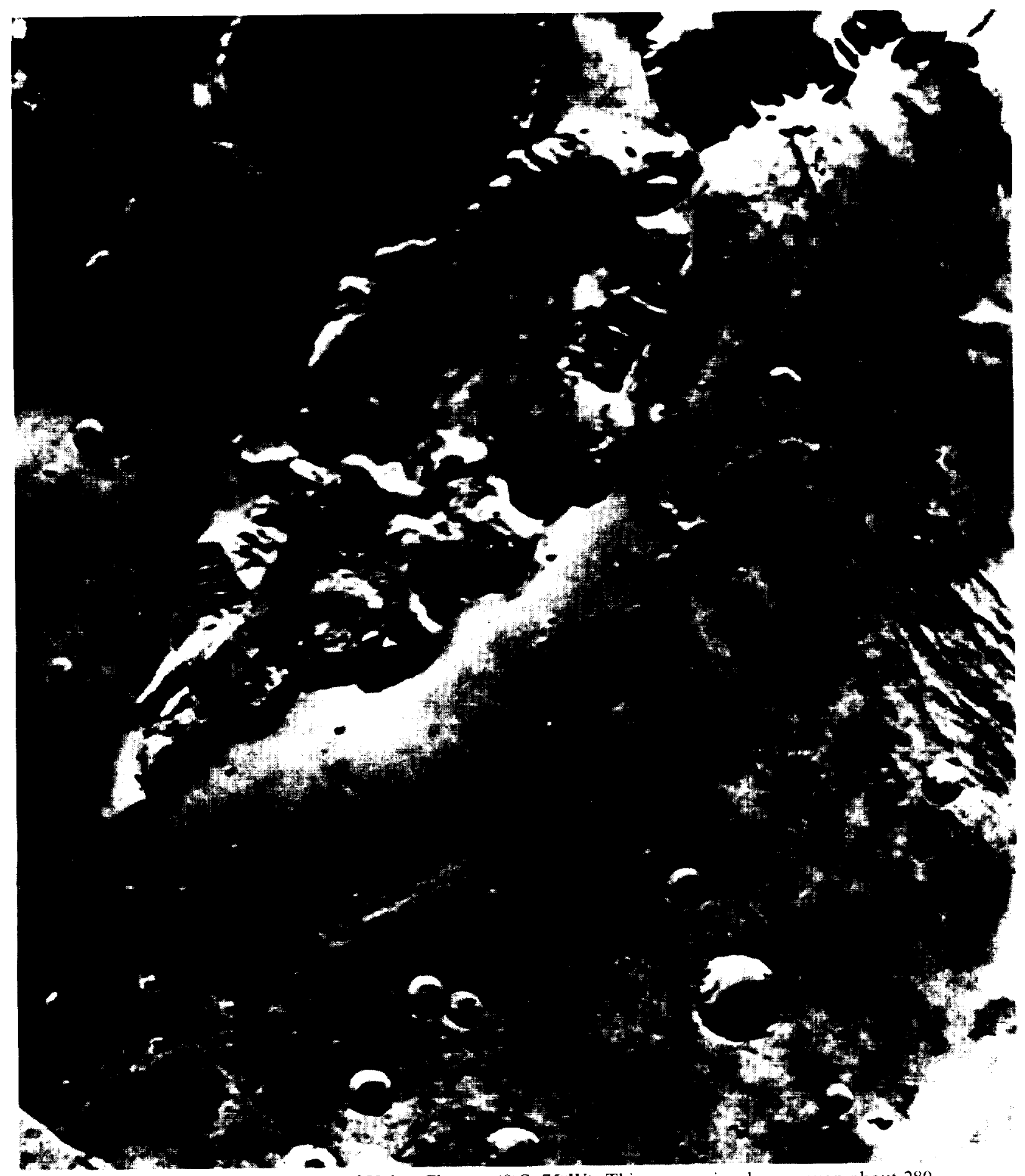

Fig. 2. Viking orbiter image of Hebes Chasma $(0 \mathrm{~S}, 75 \mathrm{~W})$. This canyon is a box canyon about 280 $\mathrm{km}$ long. The mesa in the center of the canyon shows layered deposits that are believed to have been deposited in standing bodies of water (Nedell a $a l ., 1987$ ). If all the deposits mapped by Nedell ar al. are organic then $30 \mathrm{hPa}$ of $\mathrm{O}_{2}$ would have been released 

in place, the stage would be set for the development of oxygenic photosynthesis. Evidence for the antiquity of oxygenic photosynthesis in oxic lakes as discovered by Buick (1992) from the Archean period $\left(2.7 \times 10^{9}\right.$ years ago) is consistent with our hypothesis. Given the similarity of the environments on the early Mars and early Earth it is plausible that life originated on Mars and oxygenic photosynthesis also began there at a very early stage through the action of photochemically produced oxidants.

Given biological production of $\mathrm{O}_{2}$, net oxidation is produced when the reduced organic material is sequestered into non-exchangeable sedimentary reservoirs. This does not necessarily result in the buildup of oxygen in the atmosphere. On Earth, several geological processes acted to nullify the biological production of $\mathrm{O}_{2}$. Recycling of sediments on the Earth by plate tectonics and the associated thermal processing of subducted sedimentary material exhumes and oxidizes the reduced organic material consuming any oxygen that was produced by their initial burial. Furthermore volcanic sources of reduced gases (especially $\mathrm{H}_{2}$ ) also consume $\mathrm{O}_{2}$. Together these effects limited the buildup of $\mathrm{O}_{2}$ on the Earth until about $2.5 \mathrm{Gyr}$ ago. Thus, Earth may have spent over 1 Gyr producing $\mathrm{O}_{2}$ before the titration of the sources of reductants was complete.

Mars, however, lacks plate tectonics and thus deep sedimentary layers on that planet would be more stable than on the Earth. Furthermore, volcanic activity on Mars appears significantly diminished compared to the Earth both in magnitude and duration (e.g. Greeley and Spudis, 1981). An implication of this is that while the transition to an oxidizing atmosphere on Earth required a billion years, the transition may have been much more rapid on Mars. Mars may have experienced an oxygen rich atmosphere long before the Earth and oxidizing conditions could have predated many of the surfaces on Mars. Thus, both organic and oxidized materials may be buried deep in the stratigraphic column.

We have considered a biological source by computing the oxidation produced by the net burial rate of sedimentary organic material for the Proterozoic Earth, between 2.5 and 0.8 Gyr ago, as determined by DesMarais et al. (1992) of $\simeq 10^{12} \mathrm{~mol} \mathrm{yr}$. In Fig. 1 we show the results for two cases; one in which this production rate continues for $10^{4} \mathrm{yr}$ and one in which this continues for only $10^{\mathrm{x}} \mathrm{yr}$.

If the biological production of $\mathrm{O}_{2}$ played a role in the redox state of the present Mars there must be an associated store of organic material at depth in these stable sedimentary layers. There are several sites where deep stable sedimentary layers of organic material might be found on Mars. Hebes Chasma, shown in Fig. 2, provides one such example. Nedell et al. (1987) have determined that the layered sediments in this canyon and associated canyons were probably deposited in standing bodies of water. They estimated that the total volume of sediments was $1.3 \times 10^{5} \mathrm{~km}^{3}$. We consider the limiting case; if this volume of material was entirely composed of organic material of equivalent stoichiometry $\left(\mathrm{CH}_{2} \mathrm{O}\right)$ this would have released sufficient oxygen to produce $30 \mathrm{hPa}$ of $\mathrm{O}_{2}$ comparable to the amount produced by photochemistry. Scott et al. (1991) have identified other basins on Mars which potentially contain orders of magnitude more sedimentary material. Interestingly, Wright et al. (1989) have reported trace organics in one of the SNC meteorites (EETA 79001 ), more than 400 ppm degradable organic material. The isotropic ratio of carbon 13 to carbon 12 in the organic material is suggestive of a biological origin, although terrestrial contamination in these measurements cannot be ruled out (Jakosky, 1991). The implications of these low levels of organics are not fully understood. If a layer of organic rich sediments was found on Mars it is likely that the isotopic composition of these organics could be used to determine if they were of biological origin (Schidlowski, 1992).

\section{Conclusion}

If the oxidation seen on Mars is a photochemical product, the fundamental source of oxidation is the escape of $\mathrm{H}_{2}$ to space and the active oxidant produced is $\mathrm{H}_{2} \mathrm{O}_{2}$. The resulting oxidation is limited in total amount and ability to diffuse to depth. If the oxidant is a product of biological photosynthesis, then the oxidant produced is $\mathrm{O}_{2}$. This oxidant would accumulate if the reduced carbon was buried in sedimentary basins. It is important to note that while we know that photochemical production of oxidants is occurring on Mars, any past biological source is speculative at this time. The key signature of possible sources of oxidation on Mars is the fate of the reductant produced. For photochemical processes the reductant is lost to space and only the oxidant remains. If oxidation is biological then the reduced carbon must also be found in the subsurface as occurs on Earth. If the oxidized surface layer is underlaid by a layer of organic material this could be consistent with oxygenic photosynthesis. Isotopic analysis may provide further evidence of biological origin of the organic material. Thus, the key to understanding the past oxidation history of Mars is to search for organics, be they shallow or deep.

\section{References}

Arvidson, R. E., Dust on Mars II, LPI Tech. Rep. 86-09, p. 9. 1986.

Awramik, S. M., The oldest records of photosynthesis. Pholosyn. Res. 33, $7589,1992$.

Awramik, S. M., Schopf, J. W. and Walter, M. R., Filamentous fossil bacteria from the Archean of western Australia. Precimb. Res. 20, 357-374, 1983.

Ballou, E. V., Wood, T. C., Wydeven, T., Lehwalt, M. E. and Mack, R. E., Chemical interpretation of Viking lander 1 life detection experiment. Nature 271, 644-645, 1978.

Biemann, K., Oro, J., Toulmin III, P., Orgel, L. E., Nier, A. O., Anderson, D. M., Simmonds, P. G., Flory, D., Diaz, A. V., Rushneck, D. R., Biller, J. E. and LaFleur, A. L., The search for organic substances and inorganic volatile compounds in the surfice of Mars. J. geophys. Res. 82, 4641-4658. 1977.

Buick, R., The antiquity of oxygenic photosynthesis: evidence from stromatolites in sulphate-deficient Archaean lakes. Scicnce 255, $7477,1992$.

Bullock, M. A., Stoker, C. R., McKay, C. P. and Zent, A. P., A coupled soil atmosphere nodel of $\mathrm{H}_{2} \mathrm{O}_{2}$ on Mars. Icurus 107 , $142 \cdot 154,1994$. 
Carr, M. H., D/H on Mars : effects of floods, volcanism, impacts and polar processess. Ic arus 87, 210 227. 1990.

Chyba, C. F. et al., Private communication, 1994.

DesMarais, D. J., Strauss, H., Summons, R. E. and Hayes, J. M., Carbon isotope evidence for the stepwise oxidation of the Proterzoic environment. Nature 359, 605-609 (1992).

Flynn, G. J. and McKay, D. S., An assessment of the meteoritic contribution to the martian soil. J. geophys. Res. 95, 1449714509, 1990.

Fox, J. L., On the escape of oxygen and hydrogen from Mars. Geophys. Res. Lett. 20, 1847-1850, 1993.

Fridovich, I., The biology of oxygen radicals. Science 201, 875, 1978.

Gooding, J. L., Soil mineralogy and chemistry on Mars : possible clues from salts and clays in SNC meteorites. Icarus 99, 28 $41,1992$.

Greeley, R. and Spudis, P. D., Volcanism on Mars. Ret. Geophrs. Space Phys. 19, 13-41, 1981.

Hunten, D. M., Possible oxidant sources in the atmosphere and surface of Mars. J. Mol. Evol. 14, 57 64. 1979.

Jakosky, B. M., Mars volatile evolution: evidence from stable isotopes. Icarus 94, 14-31, 1991.

Kasting, J. F., $\mathrm{CO}_{2}$ condensation and the climate of early Mars. Icarus 94, 1-13, 1991

Kasting, J. F. and Walker, J. C. G., Limits on oxygen concentration in the prebiological atmosphere and the rate of abiotic fixation of nitrogen. J. geophis. Re's. 86, 1147-1158. 1981.

Klein, H. P., The Viking biological experiments on Mars. Icarus 34, 666-674, 1978.

Levin, G. V. and Straat, P. A., Recent results from the Viking Labeled Release Experiment on Mars. J. geophys. Res. 82, 4663-4667, 1977.

Levine, J. S., Augustsson, T. R. and Natarajan, M., The prebiological paleoatmosphere: stability and composition. Origins Life 12, 245-259, 1982.

Liu, S. and Donahue, T. M., The regulation of hydrogen and oxygen escape from Mars. Icarus 28, 231-246, 1976.
McElroy, M. B., Kong, T. Y. and Yung, Y. L., Photoche nistry and evolution of Mars' atmosphere: a Viking perspective. $/$. geophys. Res. 82, 4379-4388, 1977.

McKay, C. P. and Hartman H., Hydrogen peroxide and the origin of oxygenic photosynthesis. Origins Life 21, $15^{\prime \prime} 163$. 1991.

Nedell, S. S., Squyres, S. W. and Andersen, D. W., Origin and evolution of the layered deposits in the Valles Martneris. Mars. Icurus 70, 409 441, 1987.

Owen, T., Maillard, J. P., de Bergh, C. and Lutz, B. L., Deuterium on Mars: the abundance of HDO and the value of D/H. Siche' 240, $1767 \quad 1770,1988$.

Oyama, V. I. and Berdahl, B. J., The Viking gas exchange r.xperiment results from Chryse and Utopia surface samp es. $J$. geophys. Res. 82, 4669-4676, 1977.

Pollack, J. B., Kasting, J. F., Richardson, S. M. and Poliakoff, K., The case for a wet, warm climate on early Mars. 'carus 71, 203. 224. 1987 .

Schidlowski, M.. Stable carbon isotopes : possible clues to early life on Mars. Adr, Space Res. 12(4), 101-110. 1992.

Schopf, J. W., editor, Earth's Earliest Biosphere: Its Origin and Erolution. Princeton University Press, Princeton, New J srsey, 1983.

Schopf, J. W., Microfossils of the early Archaen apex (hert: new evidence for the antiquity of life. Science $260,640646$. 1993.

Schopf, J. W. and Packer, B. M., Early Archean (3.3-billion to 3.5-billion-year-old) microfossils from Warrawoona Group, Australia. Science 237, 70 73, 1987.

Scott, D. H., Rice Jr, J. W. and Dohm, J. M., Martian palec lakes and waterways: Exobiological implications. Origins Life Evolution Biosphere 21, 189 198, 1991.

Towe, K. M., Early precambrian oxygen : a case against p rotosynthesis. Narure 274, 657, 1978.

Wright, I. P., Grady, M. M. and Pillinger, C. T., Or sanic materials in a martian meteorite. Nature 340, 146 157, 1989.

Zent, A. P. and McKay, C. P., The chemical reactivity of the martian soil and implications for future missions. I'aru: $\mathbf{1 0 8}$, $146-157,1994$. 